\title{
Utilization of Research for Elite Sport in the Czech Republic
}

\author{
Jana Nová \\ Masaryk University, Faculty of Sport Studies, Brno, Czech Republic
}

\begin{abstract}
A B S T R A C T
In 2015 and 2016, the author conducted an audit of the Czech national elite sports policy using the international research methodology called SPLISS (Sports Policy Factors Leading to International Sporting Success). Based on the audit results in Pillar 9 this paper analyses the situation regarding the existence of structural factors for the dissemination of research applicable in elite sport and the extent to which these research outputs serve as scientific input to elite sport in the Czech Republic. The results from this qualitative and quantitative study focus on the utilization of knowledge from sport science in a country context, providing the base for a comparison with other countries and proposing the way towards effective and efficient cooperation between academia and sport practice in this regard.
\end{abstract}

Key words: elite sport, utilization of research, knowledge transfer, institutionalization

\section{Introduction}

As international competition among countries in sports is becoming stronger and financial support for elite sport is increasing, national governing bodies in sport should focus on strategic approaches to develop world-class athletes. Considering this, it seems that the need to analyse the factors leading to international sports success is legitimate (De Bosscher, Shibli, Westerbeek, \& Van Bottenburg, 2015). Therefore, also in the Czech Republic analysis with regard to the Czech national elite sports system was conducted. The analysis was based on a comparative international research methodology called SPLISS (Sports Policy Factors Leading to International Sporting Success; De Bosscher et al., 2015). The data was collected in 2015 and 2016 when the author of the article conducted the research project using the SPLISS methodology. The results of the SPLISS study in the Czech Republic identified several underdeveloped elite sports policy areas that are considered to be critical for sporting success and among them also the Pillar 9 - Scientific research and innovation. According to this pillar, the search for innovation and the use of applied scientific research in the development of elite sport is seen as a key issue in the strategic development of performance in elite sport. Currently, a lot of national reports are available as a result of separate research activities mapping the situation in general, and in particular sports (Judge, Hunter, \& Gilreath, 2008; Judge, Young, \& Wanless, 2011; Martindale \& Nash, 2013; Reade, Rodgers, \& Hall, 2008; Kilic \& Ince, 2015) and also comparative studies based on SPLISS methodology (De Bosscher et al., 2015). Thus our qualitative and quantitative study focuses on the utilization of knowledge from sport science in a country context providing the base for a comparison with other countries and proposing the way towards effective and efficient cooperation between academia and sport practice in this regard.

\section{Methods}

The data was collected in a national context, employing two instruments. An inventory of conditions for, and use of, sport science in the elite sport system consists of 9 critical success factors and a qualitative approach - desk research and content analysis was applied in order to gather the relevant information with regard to the overall sport policy in this area. The second instrument used was an on-line survey conducted among elite athletes and coaches and part of a standardized, officially translated and piloted questionnaire relevant to the topic of the study (SPLISS, Pillar 9) was used. Purposive sampling was employed following the SPLISS methodology (De Boscher et al. 2015) that led to the sample of elite athletes $\mathrm{N}=847$; response rate $10.98 \%(\mathrm{n}=93)$ and the sample of elite coaches $\mathrm{N}=168$; response rate $11.9 \%(\mathrm{n}=20)$. Data collection was realized during the winter of 2015/2016. The data from the on-line survey was analysed with the IBM SPSS Statistics (24.0) software. All the information was then used to compare the situation in the Czech Republic with other countries in order to identify the gaps and to propose measures for bridging academia and elite sport and thus improve the state of the art in terms of dissemination of scientific knowledge and its utilization.

\section{Results}

Pillar 9 assesses the scientific input to elite sport, and examines the extent to which a coordinated approach to the organisation and dissemination of research and scientific information is present in the country. The athletes' and coaches' survey is complementary to the inventory performed by researchers and indicates the modes of searching for innovation and the use of applied scientific research in the development of high performance sport. The results from the overall sport policy inventory of the conditions in the elite sport system in relation to SPLISS Pillar 9 are presented in the Table 1. 
Table 1. Sport Policy Inventory - Critical Success Factors SPLISS Pillar 9

\section{There is sufficient support for scientific research and innovation and sport science is provided at each level of}

\section{CSF}

There is (sufficient) (financial) support for scientific research and innovation in elite sport.

Different areas of elite athlete development (all pillars) are supported by applied scientific research and innovation projects and there are 'field laboratories' and/or embedded scientists that in situ develop, test and/or apply new technologies in cooperation with coaches and athletes at elite sport training centres.

\section{elite sport development}

Inventory results

The Ministry of Education and Sport in the Czech Republic does not provide direct financial support for scientific research and innovation regarding elite sport. Research activities in this field are scarce and rely on the individual initiatives and interests of researchers and particular sports clubs and associations.

There are no 'field laboratories' or embedded scientists that develop, test or apply new technologies in cooperation with coaches and athletes at elite sport training centres in the Czech Republic. The new strategy for sport up to 2025 was designed recently, but there is no mention of 'field laboratories' or embedded scientists.

\section{Scientific research is collected, coordinated and disseminated among coaches and NGBs \\ CSF \\ Inventory results}

There is a national research centre that conducts applied elite sport research and coordinates research activities in elite sport nationa$1 l y$.

There is a specific responsibility within NGBs for developing and coordinating innovative research projects in elite sport.

Scientific support/innovation in elite sport is provided in strong cooperation with universities and (sport) research centres.

There is a regularly updated database of scientific research that can be consulted by coaches and NGBs.

There is a network to communicate and disseminate scientific information to NGBs, clubs, elite athletes and coaches. Coaches receive scientific information from NGBs and other organisations and use applied sport science in their training activities

Coaches make use of sport scientific information on elite sport, with regard to their sport

Scientific research is embedded in coaches' education and coaches are taught how to search for scientific information and how to use research results as part of their coaching

There is no national research centre that conducts applied elite sport research or coordinates research activities in elite sport in the Czech Republic.

There has not been any specific responsibility in the Czech Republic for developing or coordinating research and innovation projects in elite sport within the NGBs identified.

So far, there are no national agreements relating to cooperation between sport organisations and universities or sport research centres with regard to elite sport.

There is no regularly updated nationally coordinated database of scientific research specifically for elite sport that can be consulted by coaches and governing bodies.

There is no mechanism in place in the Czech Republic to inform elite coaches and sport governing bodies on a regular basis about the latest methods/ technology/ scientific research in their sport. The Ministry, NOC or respective NGBs do not organize regular conferences or events to disseminate scientific research and there is no web-based network, email newsletter or social media forum. Similarly missing are special initiatives or organizations dedicated to the increase in the uptake of sport science research results by coaches or governing bodies.

Coaches in the Czech Republic can use different types of scientific support services, i.e. in biomechanics, physiology and psychology, but this happens on the individual demand or interests and on the basis of individual agreements with relevant research centres or university units.

Scientific research and technology development is embedded in coach education in the Czech Republic, but its extent is quite limited. Demand in this area is covered by universities that organize lifelong educational courses and offer specialized higher education programmes for coaches. Thus, only those attending these courses are also taught how to search for scientific information and how to use research results as part of their coaching.

Note. CSF $=$ Critical Success Factors. NGBs $=$ National Governing Bodies. NOC $=$ National Olympic Committee

Pillar 9 in the Czech Republic is characterized by the nonstructured environment with regard to the dissemination of scientific knowledge and utilization of knowledge in elite sport. Key weaknesses are linked to the non-existence of specialised units, which could look at elite sport, and the application of science and technology into it, including data collection and analysis. The policy inventory was supplemented by the on-line athletes' survey and on-line coaches' survey.

\section{Athletes' responses}

More than one third of the athletes were not able to judge the applicability of applied scientific research (biomechanics, physiology), developments in new technology and innovation in their sport and only $24 \%$ rated the applicability of scientific research as very high and high. $32.8 \%$ of the athletes rated developments in new technology as very and fairly high. The applicability of innovations was rated as very high and high by $25.8 \%$.

One third of the athletes were not able to rate the opportunities they get to use the applied scientific research (biomechanics, physiology), developments in new technology and innovation in their sport. Just $8.6 \%$ rated the opportunity they get to use applied scientific research (biomechanics, physiology) as very high and fairly high. The low score was also assigned to developments in new technology (12\%) and innovations $(13.8 \%)$. 


\section{Coaches' responses}

Forty percent of the coaches frequently actively search for scientific information related to their training activities for the development of their elite athletes (at least once a month), $33.3 \%$ sometimes (1-2 times a year), while $26.7 \%$ do not perform this search at all.

Almost twenty seven percent of the coaches actively used applied scientific research related to their training activities for the development of their elite athletes over the past 12 months, whereas $73.3 \%$ did not. All the coaches who participated in the on-line survey stated that they do not receive at least annually from their national governing body or club, a magazine which contains, amongst other things, scientific knowledge on their sport.

Sixty percent of the coaches confirmed that their national governing body, club or national sport agency organized seminars over the past 12 months that updated them with information or relevant scientific knowledge/research. $40 \%$ responded that this did not happen in their case.

More than eighty six percent of the coaches consider that there is insufficient scientific research in the Czech Republic related to their area of elite sport and $66.7 \%$ consider that scientific knowledge is not disseminated sufficiently well amongst the elite coaches in their sport.

Almost sixty seven percent of coaches consider that scientific knowledge is disseminated sufficiently well amongst the elite coaches in their sport, while the rest of the coaches did not agree with this.

More than six percent of the coaches were not able to rate the applicability of applied scientific research (biomechanics, physiology), 13.3\% developments in new technology and 20\% innovation in their sport. $33.3 \%$ of them rated the applicability of applied scientific research (biomechanics, physiology) and developments in new technology as very high and fairly high.

Twenty percent rate the same way the applicability of innovations. At the same time, $20 \%$ of the coaches were not able to rate the opportunities they get to use applied scientific research (biomechanics, physiology), developments in new technology and innovation in their sport. $26.7 \%$ rated the opportunities they get to use applied scientific research (biomechanics, physiology), and innovations as very low and fairly low. $33.4 \%$ rated this opportunity as very low and low in the case of developments in new technology. At the same time, $6.7 \%$ of the coaches rated the opportunities they get to use applied scientific research (biomechanics, physiology) developments in new technology and innovation in their sport as very high.

As is obvious from the abovementioned results from the online survey active search for, and use of, scientific information related to training activities for the development of elite athletes is quite limited as is also the provision of a specialized magazine by the national governing bodies. Dissemination of scientific knowledge amongst elite coaches is insufficient. The applicability of applied scientific research, developments in new technology and innovation is considered by coaches as average. The majority of the elite athletes were not able to rate the applicability and opportunities coming from applied scientific research, developments in new technology and innovation in their sport.

\section{Discussion}

The results from the Czech national context confirmed that the situation with regard to a coordinated approach to the organisation and dissemination of research and scientific infor- mation into elite sport is very similar to that which can be found in the majority of studies related to this topic (Kilic \& Ince, 2015). To satisfy the need for providing opportunities to use scientific information for elite sport, the most widely used coach-to-coach knowledge transfer (Kilic \& Ince, 2015) must be supplemented by a more systematic approach that would abolish the barriers to the coaches' and athletes' access to sport science such as the time that is needed to become familiar with scientific journals and be capable of understanding sport scientists (Nová, 2015). National strategies for developing mutually beneficial communication between academia and practice that would remove the barriers in knowledge transfer are today of utmost importance not only for elite success but above all for the health benefits of elite athletes. Another source of information with regard to the comparison in the utilization of research for elite sport in the Czech Republic are the results from an international comparison of the Sport Policy Factors Leading to International Sporting Success (SPILSS 2.0) in 15 nations (de Boscher et al., 2015). The key findings from the overall inventory of critical success factors in Pillar 9 - Sport science support, scientific research and innovation in sport show that the best performing nations in summer and winter sports generally score well in scientific research and innovation. They have a national sport research centre and co-ordinate, disseminate and communicate scientific information well (de Boscher et al., 2015). The situation in the Czech Republic resembles the situation in Denmark, Spain, Portugal, Northern Ireland, Brazil and Wallonia. In these countries similarly to the Czech Republic the national co-ordination and dissemination of scientific research as well as financial support provided for research are not developed at the level comparable with Australia, Japan and Canada, where the national research centres (Australian Institute of Sport; Japanese Institute of Sport Science; network of seven Canadian Sports Centres that collaborate with NGBs) play a vital role in this sense. From the stakeholders' view (the results from the elite sport climate survey by coaches and athletes) it is perceived that there is generally room for improvement on Pillar 9 in all countries (de Boscher et al., 2015). The main findings from 15 countries are very much in tune with the findings from the survey conducted in the Czech Republic. There is a dissatisfaction among coaches with regard to the applicability and the dissemination of research data for their sport as a result of the gap that exists in the knowledge transfer from universities to sport practice. As is obvious from this international comparison for all countries, as well as for the Czech Republic, the crucial role in Pillar 9 is assigned to the existence of a national research centre that would conduct applicable research for elite sport and would be able to disseminate the results from it into elite sport practice. Collaboration with relevant universities based on formal agreement is the second most important success factor in this Pillar. Therefore, our suggestions for improvement in the above-mentioned areas focus on following aspects:

Utilization of the institutionalization theory in the process of establishing a national research centre for elite sport in the form of the one or a network of cooperating organizations

To foster the transfer of scientific results into elite sport policy, strategy and the systematic background created by a set of cooperating stakeholders / interest groups the existence of separate organizational structures responsible for the transfer of scientific results into elite sport is also missing. The institutionalization theory is based on the belief that the creation of the structures, which are also carriers of the desired values, is important when pursuing the policies in society and in a process 
of social change. If we accept the idea that effective utilization of the research by elite sport is one of the important policies of sports, we can also identify the need for its enforcement by a sufficient institutional base. The common idea that unifies difremain whereas individuals come and go. Structures (bodies) form a greater regularity in human behaviour than would noralization (Peters, 2000). To assess the extent of institutionalization the criteria proposed by Huntington (1965) and Goetz and Peters (1999) namely autonomy, adaptability, complexity, coherence, congruence and exclusivity, may help in measuring the degree of institutionalization, and hence in measuring institutions themselves. Following the concept of institutionalization, the creation of the appropriate structures and the network of mutually complementary organizations meeting all dimensions of institutionalization to support utilization of research for elite tance. Unless the network of stakeholders/interest groups is represented by the organizations that will be able

to adopt and implement their own decisions in the field of utilization of research for elite sport to generate sufficient budget for their activities even in a changing environment and at the same time they will not create unhealthy competition, it will be not possible, in our opinion, in the Czech Republic to promote long-term and sustainable strategies of utilization of research for elite sport and to ensure their implementation. ferent approaches to institutionalization is that the structures mally occur and it depends on the extent / degree of institutionsport policy within the country context is of the utmost impor-

Utilization of knowledge transfer theories for closing the gap between universities and practitioners in elite sport

As our analysis shows, it is obvious that Czech universities currently lack the appropriate forms of cooperation with elite sport practice and innovation transfer into elite sport. Therefore, we suggest implementing the measures proposed by Nová (2011).

\section{Practical implication of the paper}

This paper represents the first attempt to analyse the structural factors for the dissemination of research applicable in elite sport and the extent to which these research results serve as the scientific input to elite sport in the Czech Republic. On the basis of sound methodology and research findings, the author has proposed concrete measures using well-known theories, namely institutionalization and knowledge transfer. Implementation of the proposed measures can pave the way for improvement in the state of the art in the utilization of research for elite sport in the Czech Republic.

\section{Acknowledgements}

This article was written at Masaryk university as part of the project 'Comparison of policies for the promotion of elite sport abroad with the policies in the Czech Republic' Project: MUNI/A/1468/2014; Investor: Grant Agency of the Masaryk University - Category A.

Science, 8(1), 21-37.

De Bosscher, V., Shibli, S., Westerbeek, H., \& Van Bottenburg, M. (2015). Successful Elite Sport Policies. An International comparison of the sports policy factors leading to international sporting success (SPLISS 2.0) in 15 nations. Aachen: Meyer \& Meyer.

Goetz, K.H., \& Peters, P. (1999). Institutional Theory and Political Executives: Creating Executive Organizations East and West. Paper presented at Conference on Institutional Theory, Ross Priory, Dunb. (18-19). Scotland.

Huntington, S.P. (1965). Political Development and Political Decay, World Politics, (17).

Judge, L.W., Hunter, I., \& Gilreat, E. (2008). Using Sport Science to Improve Coaching: A Case Study of the American Record Holder in the Women's Hammer Throw. International Journal of Sports Science \& Coaching, 3(4), 477-88.

Judge, L.W., Young, M., \& Wanless, E. (2011). Using Sports Science and Training Theory to Develop Elite Performance: A Case Study of a 2005 World Championship Finalist in the Women's Shot Put. International Journal of Sports Science \& Coaching, 6(3), 365-385.

Kilic, K., \& Ince, M.L. (2015). Use of Sports Science Knowledge by Turkish Coaches. International Journal of Exercise
Martindale, R., \& Nash, C. (2013). Sport science relevance and application: Perceptions of UK coaches. Journal of Sports Sciences, 31(8), 807-19.

Nová, J. (2011). Institutional prerequisites for the Transfer of Innovation at Universities. Bruxelles: Bruylant Bruxelles. Collection Ĺ Europe Des Universités, 131- 146.

Nová, J. (2015). Institutionalized Systematic Review as a Tool for Knowledge Transfer in Sport Management. Sport Mont, XIII(43-45), 22-28.

Peters, B.G. (2000). Institutional Theory: Problems and Prospects 2000 by the Department of Political Science. Institute for Advanced Studies (HIS). Retrieved from https://www .ihs.ac.at/publications/pol/pw_69.pdf

Reade. I, Rodgers, W., \& Hall, N. (2008). Knowledge Transfer: How do High Performance Coaches Access the Knowledge of Sport Scientists? International Journal of Sports Science \& Coaching, 3(3), 319-34.

Reade, I., Rodgers, W., \& Spriggs, K. (2008). New Ideas for High Performance Coaches: A Case Study of Knowledge Transfer in Sport Science. International Journal of Sports Science \& Coaching, 3(3), 335-54.

\footnotetext{
J. Nova

Masaryk University, Faculty of Sport Studies, Kamenice 753/5, 62500 Brno, Czech Republic

e-mail:nova@fsps.muni.cz
} 